\title{
DIREITOS FUNDAMENTAIS NA PÓS- MODERNIDADE SOB A PERSPECTIVA DA ANÁLISE ECONÔMICA DO DIREITO
}

FUNDAMENTAL RIGHTS IN POST-MODERNITY UNDER THE PERSPECTIVE OF THE ECONOMIC ANALYSIS OF LAW

\author{
Emerson Ademir Borges de Oliveira ${ }^{1}$ \\ Universidade de Marília \\ Jordana Viana Payão ${ }^{2}$ \\ Universidade de Marília
}

\begin{abstract}
Resumo
A concretização dos direitos fundamentais é pauta de tradicionais debates jurídicos. A pósmodernidade, contudo, introduziu denominadores inéditos na dinâmica dos direitos fundamentais e, frente aos crescentes fenômenos da erosão da consciência constitucional e as necessárias escolhas trágicas. O objetivo do presente artigo é convidar a uma reflexão interdisciplinar do referido contexto sob a perspectiva da análise econômica do Direito, aliado ao método dialético-jurídico e à pesquisa bibliográfica nacional e estrangeira.

Palavras-chave

Direitos Fundamentais. Pós-Modernidade. Análise Econômica do Direito. Escolhas trágicas. Judicialização.
\end{abstract}

\begin{abstract}
The realization of fundamental rights is a pattern of traditional legal debates. Postmodernity, however, has introduced unprecedented denominators in the dynamics of fundamental rights, and in view of the growing phenomena of the erosion of constitutional consciousness and the necessary tragic choices. The aim of this article is to invite an interdisciplinary reflection of this context from the perspective of economic analysis of the Law, combined with the dialectical-legal method and the national and foreign bibliographic research.
\end{abstract}

Keywords

Fundamental rights. Postmodernity. Law and Economics. Tragical choices. Judicialization.

\section{Introdução}

\footnotetext{
${ }^{1}$ Mestre e Doutor em Direito do Estado pela Universidade de São Paulo. Pós-Doutor em Direito pela Universidade de Coimbra. Professor permanente e Vice-Coordenador do Programa de Mestrado e Doutorado em Direito da Universidade de Marília. Advogado e parecerista.

${ }^{2}$ Mestre e Doutoranda em Direito pela Universidade de Marília. Advogada.
} 
Revista da Faculdade Mineira de Direito | v.21 N.41 | 204

A concretização dos direitos fundamentais é pauta de tradicionais debates jurídicos. A pós-modernidade, contudo, introduziu denominadores inéditos na dinâmica dos direitos fundamentais e, frente aos crescentes fenômenos da erosão da consciência constitucional e as necessárias escolhas trágicas, o objetivo do presente artigo é convidar a uma reflexão interdisciplinar do referido contexto.

Para tanto, o referencial adotado é a Análise Econômica do Direito, a partir dos estudos desenvolvidos por Richard Posner, com a finalidade de conjugar a investigação jurídica à econômica na construção de premissas sólidas e eficientes. Associa-se, igualmente, a pesquisa bibliográfica nacional e estrangeira.

A justificativa do estudo repousa, primeiramente, na contemporaneidade da temática e o debate é rico e permite a interdisciplinaridade entre o direito e a economia. Ademais, ultrapassa fronteiras e é expressivo em escala global.

A princípio, será desenvolvida breve exposição a respeito da evolução e premissas da Análise Econômica do Direito e da importância de um estudo sistêmico do direito, favorecido pelo ponto de vista de uma análise econômica do direito, de modo a considerar a complexidade em que se insere o sistema do direito e extrair o melhor que há nos demais sistemas em busca da eficiência.

De modo a contextualizar a temática, passa-se à análise dos direitos fundamentais na pós-modernidade, estabelecendo os contornos e as demandas que contornam cenário contemporâneo e que, de certa forma, influem na concretização dos direitos fundamentais.

Pretende-se, ao final, vislumbrar as possíveis contribuições da Análise Econômica do Direito à máxima concretização dos Direitos Fundamentais em um cenário pós-moderno que, conforme se demonstrará, demanda abordagens minimamente multidisciplinares.

\section{Análise econômica do Direito}

A análise econômica do direito ventila o propósito de introduzir uma metodologia que contribua significativamente para a compreensão dos fenômenos sociais auxiliando na tomada racional de decisões jurídicas. A construção de uma percepção a respeito da importância de recorrer à análise 
Revista da Faculdade Mineira de Direito | v.21 N.41 | 205

econômica no processo de formulação das normas jurídicas de modo a torná-las cada vez mais eficientes se deu progressivamente.

$\mathrm{O}$ direito parte de uma perspectiva mais objetiva, consistente na arte de regular o comportamento humano. A economia, por sua vez, é ciência que estuda os mecanismos indutores ou não por trás do comportamento humano em um mundo de recursos escassos. E analisar o direito sob a perspectiva econômica é empregar instrumentos teóricos e empíricos econômicos e ciências afins para expandir a compreensão e o alcance do direito, aperfeiçoando o desenvolvimento, a aplicação e a efetividade da norma jurídica.

O Pós-Segunda Guerra Mundial foi marcado por um movimento Jusnaturalista, no qual não havia diferença entre análise positiva e análise normativa do direito. Havendo, então, contradição entre a Lei e o direito natural, há injustiça. Durante o século XIX foi desenvolvido o Juspositivismo a partir dos ideais de repúdio ao metafísico ou ao teológico, em contraposição ao Jusnaturalismo, consolidando, portanto, a separação entre os campos do direito, política e economia.

O juspositivismo contribuiu para a teoria jurídica ao estabelecer a distinção entre análise positiva e normativa do direito, bem como com a identificação do direito como um mecanismo de mudança social, devendo obedecer a critérios de racionalidade. Em contrapartida, a forma como a independência metodológica foi implementada e evoluiu, levou a adoção de uma postura xenófoba e hermética ao direito ${ }^{3}$.

Consequentemente, gerou-se uma carência de um instrumental analítico mais robusto como disponível nas demais ciências com as quais o direito não dialoga de fato, comprometendo a proposta de finalidade racional jurídica.

A necessidade de uma comunicação entre o direito e demais ciências, de modo a garantir a racionalidade, efetividade e otimização do ordenamento jurídico é potencializada quando se fala em economia.

O desenvolvimento da relação entre Direito e Economia sofreu resistência entre os juristas e economistas tradicionais, sob o argumento de que seriam ramos metodologicamente incompatíveis. Caberia ao Direito preocupar-se com valores de justiça, moral e ética, ao passo que a Economia

${ }^{3}$ GICO JR, Ivo. Introdução ao direito e economia. p.6. 
Revista da Faculdade Mineira de Direito | v.21 N.41 | 206

possuía como premissa máxima a eficiência. Valores, assim, teoricamente incompatíveis.

Enquanto o Direito é exclusivamente verbal, a Economia é também matemática; enquanto o Direito é marcadamente hermenêutico, a Economia é marcadamente empírica; enquanto o Direito aspira ser justo, a Economia aspira ser científica; enquanto a crítica econômica se dá pelo custo, a crítica jurídica se dá pela legalidade. Isso torna o diálogo entre economistas e juristas inevitavelmente turbulento, e geralmente bastante destrutivo ${ }^{4}$.

A denominada escola do Law and Economics, ou análise econômica do direito, foi desenvolvida a partir dos anos sessenta e composta por correntes doutrinárias variadas, como a Escola de Chicago, Escola de Yale e a Nova Economia Institucional. Ao presente artigo interessam os estudos desenvolvidos por Richard Posner que, de modo sistemático, organizou a ligação entre Direito e Economia.

Segundo Paulo Caliendo, o exemplo mais marcante da fundamentação econômica do direito, encontra-se em Posner, no entendimento do valor eficiência como a verdadeira medida do Direito ${ }^{5}$.

Na obra de Posner, a economia é utilizada para construir uma teoria explicativa dos institutos jurídicos que, segundo o autor, podem ser explicados como resultados da maximização de forma relativamente coordenada de preferências individuais. Igualmente, propõe uma teoria normativa, em que avalia como as normas legais e sanções podem afetar o comportamento dos indivíduos e, a partir dos pressupostos econômicos, quais seriam as normas jurídicas mais eficientes.

Ao tratar do que é economia, o autor afirma que:

[...] la economía es la ciencia de la elección racional en un mundo - nuestro mundo - donde los recursos son limitados en relación con las necesidades humanas. La tarea de la economía, así definida, consiste en la exploración de las implicaciones de suponer que el hombre procura

${ }^{4}$ SALAMA, Bruno Mayerhof. O que é pesquisa em direito e economia? p.5.

${ }^{5}$ CALIENDO, Paulo. Direito tributário e análise econômica do direito. p.16. 
Revista da Faculdade Mineira de Direito | v.21 N.41 | 207

en forma racional aumentar al máximo sus fines en la vida, sus satisfacciones: lo que llamaremos su "interés propio".

Portanto, os fenômenos sociais podem ser explicados a partir da racionalidade dos comportamentos dos indivíduos. Continua Posner:

El concepto del hombre como un ser racional que tratará de aumentar al máximo su interés propio implica que la gente responde a los incentivos; que si camban las circunstancias de una persona en forma tal que podría aumentar sus satisfacciones alterando su comportamiento, lo hará así ${ }^{7}$.

A ideia é que a economia possa colaborar com o direito, especialmente, por meio da elaboração de modelos de comportamento que ajudem na previsibilidade e controle das ações humanas.

A visão pelo Law and Economics é necessária para confrontar o plano da expressão com o do conteúdo, criticando o processo ideológico como instrumento de administração profissional da lei e o favorecimento da pluralidade do discurso na formulação de princípios e doutrina no Direito Civil $^{8}$.

Por conseguinte, a proposta da análise econômica do direito parte de uma perspectiva interdisciplinar mediante a aplicação das ferramentas da ciência econômica ao estudo do direito.

[...] é fundamental conhecer os fatos que condicionam o direito, como a economia. Todavia, o Direito não deve ser uma área que dependa da Economia. O Direito é uma ciência normativa, que estabelece regras, enquanto a Economia reconhece

\footnotetext{
${ }^{6}$ POSNER, Richard. El análisis económico del derecho. p.25.

${ }^{7}$ POSNER, Richard. El análisis económico del derecho. p.26.

${ }^{8}$ GORGA, Érica; SZTAJN, Rachel. Tradições do direito. p.143.
} 
Revista da Faculdade Mineira de Direito | v.21 N.41|208

fatos. Mas, para estabelecer a norma, há que se conhecer os fatos?

A economia de mercado, portanto, deve ser inspirada pelo direito que, por sua vez, considera as regras do mercado. Caso contrário, não haverá desenvolvimento.

A análise econômica do direito aplica algumas premissas econômicas, como a de que, em geral, os indivíduos coordenam seus comportamentos conforme o que consideram melhor para si mesmos, para analisar como a legislação afeta a conduta dos agentes econômicos e as relações sociais.

Ao sobrepor à superestrutura legal as suposições tracionais da análise econômica, a escola Law and Economics é capaz de utilizar o ferramental econômico não apenas para teorizar e analisar o impacto do direito sobre a economia, mas também para teorizar e avaliar a própria qualidade dos instrumentos legais, de acordo com métricas econômicas predefinidas.

As premissas fundamentais para a análise econômica do direito são universais. Além do já mencionado direcionamento do ser humano aquilo que lhe é mais vantajoso, no processo de maximização da sua utilidade, as pessoas reagem aos incentivos que recebem do ambiente em que vivem e trabalham, incluindo o sistema de preços e as regras legais que moldam os incentivos a que as pessoas estão submetidas e, portanto, influem nas suas decisões de troca, produção, consumo e investimento ${ }^{10}$.

Por conseguinte, podem ser avaliadas conforme a eficiência econômica gerada pela sua aplicação, podendo ser submetidas a prescrições normativas que tenham a finalidade de promover a eficiência do sistema econômico e social.

É possível associar Direito e Economia, tanto no plano normativonormativo como no normativo-positivo. No primeiro caso, resulta a análise das consequências das alternativas na formulação de normas de Direito positivo. O direito, por sua vez, é um sistema que influi e é influenciado pelas instituições sociais existentes na comunidade em que se aplica.

\footnotetext{
${ }^{9}$ WALD, Arnold et al. A empresa no terceiro milênio.

${ }^{10}$ PINHEIRO, Armando Castelar; SADDI, Jairo. Direito, economia e mercados. p.69.
} 
Revista da Faculdade Mineira de Direito | v.21 N.41 209

Portanto, os fatores econômicos fatalmente estão envolvidos no processo de criação de normas ${ }^{11}$.

Além de auxiliar em juízos de diagnóstico e prognose, a análise econômica do direito pode contribuir para a explicação da própria razão de existência de uma determinada norma jurídica. Isto por que, a análise econômica é caracterizada por um método de investigação, como meio para compreensão de toda e qualquer decisão individual ou coletiva.

Nesse ponto, a Law and Economics nada mais é que a aplicação do instrumental analítico e empírico da economia, em especial da microeconomia e da economia do bem-estar social, para se tentar compreender explicar e prever as implicações fáticas do ordenamento jurídico, ou seja, uma abordagem econômica para compreender o direito no mundo e o mundo no direito ${ }^{12}$.

Nesse contexto as questões postas são (i) quais são as consequências de um dado arcabouço jurídico, isto é, de uma norma jurídica especifica e (ii) qual regra jurídica deveria ser adotada?

Existem três premissas para a aplicação da Análise Econômica do Direito, a começar pela máxima de que os indivíduos são racionais, portanto, orientam suas escolhas à maximização dos seus interesses. E, para tanto, reagem a incentivos, fazendo escolhas conforme a utilidade aos seus interesses. A segunda premissa, diz respeito ao equilíbrio, já que em algum momento as atuações individuais influenciam o mercado de maneira equilibrada. E, enfim, a terceira premissa diz respeito à eficiência, partindo do fato incontroverso de que as necessidades são sempre crescentes, ao passo que os recursos são escassos ${ }^{13}$.

Os modelos de eficiência adotados pelo Law and Economics são conhecidos como "Ótimo de Pareto" e "Kaldor-Hicks". O primeiro foi desenvolvido pelo francês Vilfredo Pareto. Para ele, uma situação é eficiente quando não é possível melhorar a posição de uma das partes envolvidas sem piorar a posição de outra parte. Por outro lado, pelo modelo de KaldorHicks, dada situação é considerada eficiente quando o prejuízo causado a determinada parte é menor do que o proveito da coletividade, possibilitando

\footnotetext{
${ }^{11}$ SZTAJN, Rachel. Law and economics. p.81-83.

${ }^{12}$ CARVALHO, Cristiano. A análise econômica da tributação. p.10.

${ }^{13}$ CARVALHO, Cristiano. A análise econômica do direito tributário. p.187.
} 
Revista da Faculdade Mineira de Direito | v.21 N.41 210

que as perdas possam ser compensadas pelos ganhos, gerando a maximização da riqueza social.

Em meio aos múltiplos cenários em que se desenvolvem diálogos interdisciplinares, a esfera dos direitos fundamentais, paulatinamente, tornase terreno fértil à economia, na condição de instrumento investigativo e analítico da efetivação dos direitos fundamentais ante os fenômenos da erosão da consciência constitucional e escolhas trágicas.

\section{Direitos fundamentais na pós-modernidade}

Até o momento, não há uma definição consensual para o termo "pós-moderno", uma vez que maioria dos seus partidários recusa, em primeiro lugar, a linguagem e a lógica da definição, sugerindo que essa é uma das formas de imperialismo intelectual que ignora a fundamental incontrolabilidade do significado.

O debate europeu polariza-se entre as correntes alemã e francesa, sendo Jürgen Habermas o principal representante da primeira corrente. A segunda corrente tem como ícones Jean-François Lyotard, Michel Foucault, Jacques Derrida, entre outros.

A primeira empenha-se na defesa da posição moderna e nas potencialidades do debate emancipatório da razão iluminista e identifica os pressupostos pós-modernos com a emergência de tendências políticas e culturais neoconservadoras. A segunda corrente, determinada na valorização da "condição pós-moderna", avalia com otimismo o declínio do prestígio das narrativas mestras - metanarrativas -, como o marxismo e o liberalismo, e a liquidação dos traços iluministas do projeto moderno.

$\mathrm{Na}$ visão de Lyotard, a pós-modernidade é positiva quando retira do desencanto com o passado iluminista e racionalista energias para forjar um futuro mais capaz de conviver com a diversidade e a fragmentação:

Aos olhos revolucionários, a pós-modemidade é reformista. Aos olhos iluministas ela é uma freguesa contumaz, ou seja, mais uma rebelião anárquica da irracionalidade. Aos olhos verdadeiramente modernos, ela é apenas modernizadora. Porém, aos seus próprios olhos, a 
Revista da Faculdade Mineira de Direito | v.21 N.41 211

pós-modernidade é antitotalitária, isto é, democraticamente fragmentada, e serve- para afiar a nossa inteligência para o que é heterogêneo, marginal, marginalizado, cotidiano, a fim de que a razão histórica ali enxergue novos objetos-deestudo. Perde-se a grandiosidade, ganha-se a tolerância. Em lugar do dever histórico do Homem, tem-se a integração plena do cidadão em comunidades. E é a estas "placas" de sociabilidade que se dirige o olhar pós-moderno, buscando compreende-las ao mesmo tempo na sua autenticidade na sua precariedade ${ }^{14}$.

A modernidade não teria sido bem-sucedida nos seus objetivos, pois não conseguiu minimizar os problemas da Humanidade e seu ideário teria se exaurido no século XX, com a constatação da impotência do seu discurso e das suas propostas grandiloquentes para enfrentar, de fato, os problemas emergentes em uma sociedade hipercomplexa, globalizada, fragmentada e descentrada.

O papel da globalização foi determinante no processo, principalmente no que se refere à intensificação das relações sociais em escala mundial, ligando localidades distantes de tal maneira que acontecimentos locais são modelados por eventos ocorridos do outro lado do mundo. Em circunstâncias globalizantes aceleradas, o Estado-nação torna-se muito pequeno frente aos desafios da humanidade, ao mesmo tempo em que as relações sociais se tornam lateralmente esticadas ${ }^{15}$.

O contexto inviabiliza a ordem e o controle próprios da era moderna, a busca por respostas torna-se cada vez mais desafiadora e a liberdade do indivíduo, valor supremo durante à modernidade, adquire contornos nunca antes imaginados, desconhecendo limites a nível global e, por conseguinte, os custos não tardam a aparecer, como aspectos ambientais, sociais e culturais.

${ }^{14}$ LYOTARD, Jean-François. A condição pós-moderna. p.127.

${ }^{15}$ GUIDDENS, Anthony. As consequências da modernidade. p.59. 
Revista da Faculdade Mineira de Direito | v.21 N.41 212

A era pós-moderna, de certa forma, faz emergir a conscientização de que é preciso considerar a complexidade envolta no mercado econômico, além da dinâmica produção-consumo-lucro. Aspectos ambientais, sociais e até culturais não podem ser negligenciados em nome da plena liberdade individual, como o foi por longos períodos modernos.

Os avanços nas ciências e na técnica multiplicaram e generalizaram os riscos para a humanidade. São tantos e tão variados os fatores que podem influir num determinado evento, que se tornam muito mais difíceis as previsões e medidas acauteladoras, num contexto que corrobora as ideias da teoria científica do caos.

É possível adiantar que o pós-modernismo descrê na razão, na qual vislumbra um instrumento de repressão e intenta desconstruir as principais categorias conceituais da Modernidade, como as ideias de sujeito, progresso, verdade e justiça. Prefere o particular ao universal, o micro ao macro, o efêmero ao definitivo, o sentimento à razão. A pós-modernidade expressa a celebração do fluxo, da dispersão e da pluralidade, típicos de um cenário globalizado.

Edgar Morin desenvolveu uma crítica ao que ele considera os três pilares da ciência moderna: a ordem, a separabilidade e as lógicas indutiva e dedutiva. A busca da ordem sempre foi o interesse principal da ciência. Quando desconhecemos como algo funciona, aquilo é caótico para a humanidade. A complexidade é que garante a liberdade, pois livra o ser humano do determinismo ${ }^{16}$.

A própria "evolução" dos direitos fundamentais, se é que poderia assim ser chamada, como proposta por Paulo Bonavides, sugere o caminho para a complexidade. Inicialmente, a primeira dimensão dos direitos fundamentais privilegiando os direitos civis e políticos, como a liberdade individual em contrapartida a uma abstenção estatal. Os direitos de segunda dimensão, por sua vez, objetivam a garantia não apenas da liberdade e da autonomia perante o Estado, mas também a emancipação do ser humano por intermédio do Estado, sob a premissa de que para que o ser humano seja livre é preciso que tenha um nível de vida digno, em termos educacional, alimentar, cultural e de saúde ${ }^{17}$.

\footnotetext{
${ }^{16}$ MORIN, Edgar. A via para o futuro da humanidade. p. 23

${ }^{17}$ BONAVIDES, Paulo. Curso de direito constitucional. p.578.
} 
Revista da Faculdade Mineira de Direito | v.21 N.41 | 213

Por fim, a partir da terceira dimensão surgem os direitos transindividuais que, de certa forma, expressam as preocupações pósmodernas, relacionados ao desenvolvimento, ao meio ambiente, à autodeterminação dos povos, o acesso à informação, entre outros; direitos estes que, por sua vez, demandam uma visão interdisciplinar para serem compreendidos e garantidos em sua plenitude.

As projeções da pós-modernidade sobre o Direito são ainda controvertidas e incertas. Daí a pertinência da análise a respeito da eficácia dos Direitos Fundamentais no contexto pós-moderno, sob a perspectiva da sua efetividade.

O contexto pós-moderno e globalizado desenvolve-se em meio a uma ruptura entre o Poder e a Política. A princípio, poder e política compunham o Estado paralelamente, porém, a globalização conduzira à separação entre ambos. Política consiste na capacidade de estabelecer as medidas necessárias ao enfrentamento de crises e o poder na capacidade de efetivá-las. Portanto, a separação entre poder e política consiste no fator fundamental da incapacidade dos Estados em superar a crise. Afinal, o poder hoje se encontra no âmbito global, pertencente ao poderoso mercado econômico transnacional e, a política, permanece enfraquecida no âmbito local.

As decisões são tomadas em outra parte pelos poderes estabelecidos, que, como são supranacionais por sua própria natureza, não são instados a observar leis e regulamentos locais. Estão livres de limitações de conveniência política, bem como de necessidades de natureza social, em nome da objetividade e de um princípio de equidade que não expressa a verdadeira justiça ${ }^{18}$.

Há, portanto, um enfraquecimento das funções institucionais do Estado, repercutindo diretamente na efetivação das políticas públicas e, por conseguinte, na efetivação dos direitos fundamentais.

A partir do exposto, tomando como premissa a ideia de que a crise do Estado é, também, uma crise da sociedade, da democracia e da cidadania, não nos será difícil sustentar - a exemplo do que já tem

${ }^{18}$ BAUMAN, Zygmund; BORDONI, Carlo. Estado de crise. p. 23. 
Revista da Faculdade Mineira de Direito | v.21 N.41 | 214

ocorrido no seio da doutrina - a existência de uma crise dos direitos fundamentais, crise que - à evidência - será mais ou menos aguda, quanto maior for o impacto dos efeitos negativos da globalização econômica e da ampla afirmação do paradigma neoliberal, de modo especial nos países tidos como periféricos ou em desenvolvimento, até mesmo diante de seu grau de dependência dos países industrializados, dependência esta que tende a se tornar cada vez maior, aprofundando, por sua vez, os sintomas da crise já referida ${ }^{19}$.

Sob o impacto da globalização, o Estado se debilita, na medida em que vai perdendo o domínio sobre as variáveis que influem na sua economia. Deteriora-se a sua capacidade de formulação e implementação de políticas públicas, de regulamentação e fiscalização do seu mercado interno, e, com isso, o seu poder de garantir a eficácia dos direitos sociais ${ }^{20}$.

A força normativa da Constituição Federal passa a ser negligenciada e emerge o fenômeno da "erosão da consciência constitucional".

A expressão utilizada pelo Ministro Celso de Mello no julgamento da ADI 1.484/DF, com base nos estudos desenvolvidos por Karl Loewenstein $^{21}$, refere-se à abstenção do Poder Público, total ou parcial, na implementação das políticas públicas definidas no próprio texto constitucional, transgredindo a própria integridade da Lei Fundamental.

Representa um desprezo à força normativa constitucional, limitando todo o rol de direitos fundamentais uma a mera "carta de intenções". Daí a ilegitimidade deste comportamento negativado do Estado.

Nesse aspecto, observou Eros Grau antes mesmo da elaboração da nova Carta: "Cumpre-nos, pois, desmistificar a Constituição, conferindo imediata eficácia e aplicação a suas disposições, inclusive às ditas

\footnotetext{
${ }^{19}$ SARLET, Ingo Wolfgang. Os direitos fundamentais sociais na Constituição de 1988. p.1.

${ }^{20}$ SARMENTO, Daniel. Direitos fundamentais e relações privadas. p.25.

${ }^{21}$ LOEWENSTEIN, Karl. Teoría de la Constitución. p.222.
} 
Revista da Faculdade Mineira de Direito | v.21 N.41 215

programáticas" 22 . Constituição não é mera carta de intenções; modelo sobre a qual o Estado na medida do possível irá se guiar. Constituição é compromisso. É dívida perante a sociedade da tutela dos direitos por ela instituídos.

A problemática da eficácia dos direitos fundamentais é de ordem substancial no tocante à Constituição. Sem a eficácia dos direitos que ela promete não existe a menor razão de ser em sua existência. Ou seja, há natural perda de finalidade. Nesse sentido, Eros Grau: "Todos os seus preceitos hão de ter eficácia e aplicação imediatas, eis que somente assim deixará ela de cumprir o papel de instrumento de engodo e ilusão do povo"23. Ou, conforme Hesse: "A Constituição adquire força normativa na medida em que logra realizar essa pretensão de eficácia"24.

A complexidade da sociedade contemporânea realça o disparate entre a escassez de recursos e as crescentes demandas fundadas nos direitos fundamentais e, quando instado a agir, o Estado, acaba posto frente às escolhas trágicas. Seja no âmbito do Poder Executivo, quando do planejamento e da execução das políticas públicas, seja no âmbito do Poder Judiciário, quando da judicialização dos direitos fundamentais ${ }^{25}$.

A expressão "escolhas trágicas" tem como fundamento uma das premissas fundamentais da economia: os recursos são escassos e as demandas infinitas. E esta condição é inescapável na oportunidade da elaboração de uma política social.

Nessa ordem, salutares as palavras de Gustavo Amaral:

A escassez de recursos, a escassez de meios para satisfazer direitos, mesmo fundamentais, não pode ser descartada. Surgindo esta, o Direito precisa estar aparelhado para dar respostas. Certamente na

${ }^{22}$ GRAU, Eros Roberto. A constituinte e a Constituição que teremos. p. 45 .

${ }^{23}$ GRAU, Eros Roberto. A constituinte e a Constituição que teremos. p.46.

${ }^{24}$ HESSE, Konrad. A força normativa da Constituiçãa. p.16.

25 "O Judiciário, ao apreciar demandas individuais ou coletivas relativas a pretensões positivas, deve ponderar o grau de essencialidade da pretensão, em função do mínimo existencial e a excepcionalidade da situação, que possa justificar a decisão alocativa tomada pelo Estado que tenha resultado no não-atendimento da pretensão". AMARAL, Gustavo. Direito, escassez e escolha. p.127. 
Revista da Faculdade Mineira de Direito | v.21 N.41 216

quase totalidade dos países não se conseguiu colocar todos dentro do padrão aceitável de vida, o que comprova não ser a escassez, quanto ao mínimo existencial, uma excepcionalidade, uma hipótese limite e irreal que não deva ser considerada seriamente ${ }^{26}$.

Deve-se, portanto, ter em mente que o cobertor é sempre curto e, assim, a "tragicidade" está no fato de que alguém sempre deixará de ser beneficiário de uma política pública, em razão da opção governamental pelo atendimento de outro problema. Assim, a despeito das dificuldades apresentadas, talvez a "saída" esteja mesmo numa certa focalização, ou melhor, numa priorização de determinadas políticas que estejam diretamente ligadas às pré-condições de um processo de desenvolvimento, como é o caso da saúde e educação básica. Eis a luz do "mínimo existencial".

Tomamos por base, outrossim, que os direitos, todos os direitos, porque não são uma dádiva divina nem frutos da natureza, porque não são autorrealizáveis nem podem ser realisticamente protegidos num Estado falido ou incapacitado, implicam a concepção social e a responsabilidade individual. Daí a necessidade de vê-los como liberdades privadas com custos públicos $^{27}$.

A conjuntura socioeconômica pós-moderna e a repercussão na concretização dos direitos fundamentais é um convite à reflexão a respeito das potencialidades da análise econômica do direito como contribuição à plena efetividade constitucional.

\section{Contribuições da análise econômica do Direito à concretização dos direitos fundamentais}

A compreensão do Direito distanciado da realidade social, política e econômica não é suficiente para dar conta da complexidade da sociedade

${ }^{26}$ AMARAL, Gustavo. Direito, escassez e escolha. p.102.

${ }^{27}$ NABAIS, José Casalta. A face oculta dos direitos fundamentais. p.19. 
Revista da Faculdade Mineira de Direito | v.21 N.41 217

contemporânea. É utópico entender que a mera eficácia formal das normas jurídicas será suficiente para garantir que, em todas as hipóteses, a finalidade para a qual tais normas foram delineadas serão alcançadas.

A erosão da consciência constitucional, propriamente, é exemplo disto. Portanto, o direito, sob uma abordagem autorreferencial, enfrenta dificuldades na formatação de uma estrutura normativa adequada à concretização dos direitos fundamentais.

Vale lembrar que o "direito inadequado em grau extremo é um dos principais causadores da pobreza e da violência"28.

Neste passo, pode-se afirmar que o Direito formatado de maneira inadequada é um dos principais causadores da não concretização dos direitos fundamentais.

$\mathrm{E}$ isso pode ser atribuído, na esteira do entendimento doutrinário examinado, ao fato da ciência jurídica não possuir uma teoria sobre o comportamento humano. Nesta medida, acabam havendo situações nas quais a falta de um instrumental adequado para prospectar a reação dos atores sociais frente às estruturas jurídicas acaba por ocasionar o advento de atuações estatais (legislativas, executivas e judiciárias) inadequadas, que acabam ou não sendo efetivas aos fins a que se lançam, ou acabam ocasionando até mesmo efeitos contrários.

Para suprir esta deficiência, importante o auxílio do ferramental analítico desenvolvido por outras ciências sociais, em especial o oriundo da ciência econômica.

Considerando que a Economia tem por objeto o estudo do comportamento humano no que se refere a ordenação e administração de recursos em um contexto de escassez ${ }^{29}$, acaba expressando uma teorização do comportamento humano com significativo potencial de previsibilidade das condutas, que pode ser aplicado para avaliação das prováveis reações dos atores sociais perante a conformação das instituições jurídicas.

Sob a perspectiva da análise econômica do direito, há contribuição para a concretização dos direitos fundamentais à medida que fornece instrumental útil ao exame das políticas públicas selecionadas pelo Estado,

${ }^{28}$ GALDINO, Flávio. Introdução à teoria dos custos dos direitos. p.269.

${ }^{29}$ NUSDEO, Fábio. Curso de economia. p.44. 
Revista da Faculdade Mineira de Direito | v.21 N.41 218

conforme sua eficiência (ou não) para a máxima concretização dos direitos fundamentais.

Ademais, nesse diapasão, as políticas públicas, em sentido amplo, serão eficientes, desde que resultem em uma estrutura de incentivo que estimule o comportamento dos agentes de maneira consentânea à efetivação dos direitos fundamentais, com o máximo aproveitamento dos recursos.

$\mathrm{E}$, neste ponto, não há que se falar em incompatibilidade entre os valores da justiça e eficiência, ao contrário, complementam-se.

É natural imaginar que o direito não deve tratar de eficiência, mas de justiça. Ocorre que, em certas situações, ele versa sobre ambas, podendo criar incentivos para que as pessoas se comportem de maneira mais produtiva, num grau de eficiência econômica tendente à realização de objetivos constitucionais, como o desenvolvimento nacional. É também por meio de arranjos jurídicos que esse aumento de produtividade pode gerar, paralelamente, maior justiça social em virtude de regras de redistribuição de riquezas e redução de desigualdades. No fluxo desse diálogo, assumem voz ativa as abordagens sobre direito e desenvolvimento (Law and Development), evidenciando a interseção entre teorias econômicas, arranjos jurídicos e práticas institucionais ${ }^{30}$.

O dinamismo socioeconômico pós-moderno exige abordagens proporcionalmente complexas aos seus desafios. Os direitos fundamentais não fogem à tendência, especialmente, tendo em vista fenômenos como as ditas erosão da consciência constitucional e as escolhas trágicas que, uma vez tratadas sob visão jurídica reducionista, tendem à injustiça.

A eficiência posta à frente dos direitos fundamentais, conforme prega Richard Posner, não seria critério único e suficiente para os problemas postos no direito ${ }^{31}$. A maximização da riqueza teria que ser encarada sob o ponto de vista mais amplo, em que o Direito é um instrumento para a realização de fins sociais.

Nas palavras de Posner, em algum momento, "mesmo o indivíduo fortemente comprometido com a análise econômica do direito terá que

\footnotetext{
${ }^{30}$ ASSUNÇÃO, Matheus Carneiro. Incentivos fiscais e desenvolvimento econômico. p.7.
}

${ }^{31}$ POSNER, Richard. El análisis económico del derecho. p.23. 
tomar uma posição em questões de filosofia política e de filosofia moral". Tal fato conduz ao problema da colisão entre direitos fundamentais ${ }^{32}$.

A análise econômica do direito, por sua vez, pode representar instrumental útil quando diante das escolhas trágicas, precedentes da colisão entre princípios de direitos fundamentais.

A distinção entre regras e princípios parte da premissa de que estes são normas que ordenam que algo seja realizado na maior medida possível dentro das possibilidades jurídicas e fáticas existentes. São, por conseguinte, mandamentos de otimização, caracterizados por serem satisfeitos em graus variados e pelo fato de que a medida devida de sua satisfação não depende somente das possibilidades fáticas, mas também das possibilidades jurídicas. Já a regra vale na exata medida de suas prescrições ${ }^{33}$.

No caso da colisão entre princípios, esclarece Alexy que:

(...) os princípios têm pesos diferentes e que o princípio com maior peso tem precedência. Conflitos entre regras ocorrem na dimensão da validade, enquanto as colisões entre princípiosvisto que só princípios válidos podem colidirocorrem, para além dessa dimensão, na dimensão de peso $^{34}$.

Portanto, o princípio da máxima efetividade dos direitos fundamentais exige que o intérprete faça com que o direito fundamental atinja a sua realização plena. O princípio da máxima efetividade ou da interpretação efetiva tem o condão de conferir à norma constitucional notadamente em matéria de direitos fundamentais - a interpretação que maior efetividade lhe proporcione, ou seja, que favoreça ao máximo a realização concreta dos propósitos da norma no plano dos fatos ${ }^{35}$.

${ }^{32}$ POSNER, Richard. El análisis económico del derecho. p.23.

${ }^{33}$ ALEXY, Robert. Teoria dos direitos fundamentais. p. 90 .

${ }^{34}$ ALEXY, Robert. Teoria dos direitos fundamentais. p.94.

35 SILVA NETO, Manoel Jorge e. O princípio da máxima efetividade e a interpretação constitucional. p.95. 
Revista da Faculdade Mineira de Direito | v.21 N.41 220

As bases da análise econômica do direito compatibilizadas às premissas constitucionais, a partir da análise positiva e normativa voltada à máxima efetividade dos direitos fundamentais, representa o subsídio econômico ao direito.

O ponto fundamental, quando se fala na atuação do Poder Público, especialmente em termos de políticas públicas, na efetivação dos direitos fundamentais, não é tanto se eficiência pode ser igualada à justiça, mas sim como a construção da justiça pode se beneficiar da discussão de prós e contras, custos e benefícios. Noções de justiça que não levem em conta as prováveis consequências de suas articulações práticas são, em termos práticos, incompletas.

O Poder Judiciário, por sua vez, tendo em vista o crescente movimento da judicialização dos direitos fundamentais, em decorrência, dentre outros fatores, da descrença do cidadão nas instituições do Poder Executivo, potencializa possíveis efeitos negativos a partir de decisões judiciais que desconsideram a complexidade em torno de dada política pública, vislumbrando, exclusivamente, a justiça como efetivação daquele direito fundamental objeto da demanda.

Os instrumentais fornecidos pela análise econômica do direito podem auxiliar o desenvolvimento de decisões judiciais eficientes e, por conseguinte, justas. A considerar a escassez de recursos frente às demandas pelos direitos fundamentais, igualmente legítimas, a perspectiva multidisciplinar figura como a melhor abordagem judicial.

Num conjunto com eventuais complementações de outras ciências sociais, o instrumento teórico da Análise Econômica do Direito pode ser utilizado antes da aprovação de qualquer projeto legislativo ou da consolidação de determinada orientação interpretativa jurisprudencial, como uma espécie de análise de impacto socioeconômico da futura lei ou interpretação jurisprudencial.

De tal modo que, aumentar-se-ia consideravelmente a probabilidade de que as atuações estatais concretizadoras dos direitos fundamentais efetivamente cumprissem sua função. Isso não significa reduzir as ações estatais apenas às que sejam eficientes economicamente, mas sim levar em conta o ferramental da Análise Econômica do Direito para, em conjunto com os valores éticos e morais, definir formas de atuação que impliquem na máxima efetivação dos direitos fundamentais. 
Revista da Faculdade Mineira de Direito | v.21 N.41 221

\section{Conclusão}

A sociedade pós-moderna demanda abordagens interdisciplinares dos fatos sociais, de modo que o direito, de maneira autorrreferencial, distanciado da realidade social, política e econômica, é incompatível com a dinamicidade e complexidade contemporâneas.

A pós-modernidade refuta análises reducionistas e ordenadoras, preconizando diversidade, comunicação, enfim, multidisciplinariedade. A ciência jurídica não foge à regra.

As consequências da era moderna e globalizante contribuíram ao enfraquecimento institucional dos Estados e, por conseguinte, na efetivação das normas constitucionais consagradoras de Direitos Fundamentais.

A análise econômica do direito, nesse tocante, prestou relevante serviço na condição de campo do conhecimento cuja premissa consiste na utilização dos ferramentais do ramo da economia ao ramo do direito, seja no momento da elaboração da legislação, seja no momento da judicialização dos direitos ou execução das políticas públicas, de modo a alcançar a máxima eficiência.

Contribuiu, assim, com a identificação do que é injusto, posto que toda regra que gera desperdício e injusta e na constatação de que é impossível qualquer exercício de ponderação se quem o estiver realizando não souber o que está efetivamente em cada lado da balança, isto é, sem a compreensão das consequências reais dessa ou daquela regra.

Além disso, auxiliou a descobrir o que realmente se obtém com dada política pública e o que está se abrindo mão para alcançar aquele resultado.

Se, de um lado, é certo que os preceitos constitucionais, mormente seus objetivos e fundamentos não podem ficar à mercê de maior efetividade, de outro lado a análise econômica do direito permite identificar os demais elementos que circunstanciam qualquer efetivação de direitos que represente custos. Por outra via, permite reconhecer a inexistência de motivos financeiros e a má alocação dos recursos públicos, o que tem sido utilizado, muitas vezes, como argumento para justificar inefetividades.

\section{Referências}


Revista da Faculdade Mineira de Direito | v.21 N.41 222

ALEXY, Robert. Teoria dos direitos fundamentais. São Paulo: Malheiros, 2008.

AMARAL, Gustavo. Direito, escassez e escolha: critérios jurídicos para lidar com a escassez de recursos e as decisões trágicas. 2.ed. Rio de Janeiro: Lumen Juris, 2010.

ASSUNÇÃO, Matheus Carneiro. Incentivos fiscais e desenvolvimento econômico: a função das normas tributárias indutoras em tempos de crise. Brasília: ESAF, 2010.

BAUMAN, Zygmund; BORDONI, Carlo. Estado de crise. 1.ed. Rio de Janeiro: Zahar. 2014.

BONAVIDES, Paulo. Curso de Direito Constitucional. Malheiros: São Paulo. 2016.

CALIENDO, Paulo. Direito Tributário e análise econômica do Direito: uma visão crítica. Rio de Janeiro: Elsevier, 2009.

CARVALHO, Cristiano. A análise econômica da tributação. In: TIMM, Luciano (Org.). Direito e Economia no Brasil. 2. ed. São Paulo: Atlas. 2014. p.246-265.

. A análise econômica do Direito Tributário. In: SCHOURI, Luís Eduardo (Coord). Direito tributário: homenagem à Paulo Barros de Carvalho. São Paulo: Quartier Latin, 2008.

GALDINO, Flávio. Introdução à Teoria dos Custos dos Direitos:

Direitos não nascem em árvores. Rio de Janeiro: Lumen Juris, 2005.

GICO JR, Ivo. Introdução ao Direito e Economia. In: TIMM, Luciano (Org.). Direito e Economia no Brasil. 2. ed. São Paulo: Atlas, 2014. p.133. 
GORGA, Érica; SZTAJN, Rachel. Tradições do Direito. In: ZYLBERSZTAJN, Décio e SZTAJN, Rachel (Org.). Direito \&

Economia: Análise Econômica do Direito e das Organizações. 2. ed. Rio de Janeiro: Elsevier, 2005. p.1-15.

GRAU, Eros Roberto. A constituinte e a Constituição que teremos. São Paulo: Revista dos Tribunais, 1985.

GUIDDENS, Anthony. As consequências da Modernidade. São Paulo: Unesp, 1991.

HESSE, Konrad. A força normativa da Constituição. Porto Alegre: Sérgio Antonio Fabris, 1991.

LYOTARD, Jean-François. A condição Pós-Moderna. Rio de Janeiro: José Olympio, 2009.

LOEWENSTEIN, Karl. Teoría de la Constitución. 2. ed. Barcelona: Ariel, 1983.

MORIN, Edgar. A via para o futuro da humanidade. Bertrand Brasil: Rio de Janeiro. 2015.

NABAIS, José Casalta. A face oculta dos direitos fundamentais: os deveres e os custos dos direitos. Revista Direito Mackenzie, São Paulo, ano 3, n.2, 2002, p.9-30.

NUSDEO, Fábio. Curso de Economia: Introdução ao Direito Econômico. 4.ed. São Paulo: Revista dos Tribunais, 2005.

PINHEIRO, Armando Castelar; SADDI, Jairo. Direito, Economia e Mercados. Rio de Janeiro: Campus, 2005.

POSNER, Richard. El análisis económico del derecho. 2 ed. México: Fondo de Cultura Económica, 2007. 
Revista da Faculdade Mineira de Direito | v.21 N.41 224

Press, 1995.

Overcoming Law. Cambridge: Harvard University

SALAMA, Bruno Mayerhof. O que é pesquisa em direito e economia? Cadernos Direito GV, São Paulo, estudo 22, v. 5, n. 2, 2008.

SARLET, Ingo Wolfgang. Os direitos fundamentais sociais na Constituição de 1988. Revista Diálogo Jurídico. Salvador, ano I, v. I, n.1, abr. 2001. p.1-46.

SARMENTO, Daniel. Direitos Fundamentais e Relações Privadas. Rio de Janeiro: Lumen Juris. 2010.

SILVA NETO, Manoel Jorge e. O Princípio da Máxima Efetividade e a Interpretação Constitucional. São Paulo: LTR, 1999.

SZTAJN, Rachel. Law and Economics. In: ZYLBERSZTAJN, Décio; SZTAJN, Rachel (Org.). Direito e Economia: Análise Econômica do Direito e das Organizações. 2. ed. Rio de Janeiro: Elsevier, 2005. p.74-83.

WALD, Arnold. A empresa no terceiro milênio. São Paulo: Juarez de Oliveira, 2005. 